OPEN ACCESS

Edited by:

David Wolfe Corne,

Heriot-Watt University,

United Kingdom

Reviewed by:

Sebastian Ahnert,

University of Cambridge,

United Kingdom

Ka-Chun Wong,

City University of Hong Kong,

Hong Kong

*Correspondence:

Taha Yasser

taha.yasseri@oii.ox.ac.uk

Specialty section:

This article was submitted to Big Data

a section of the journal

Frontiers in Digital Humanities

Received: 29 September 2016

Accepted: 04 May 2017

Published: 09 June 2017

Citation:

Yan P and Yasseri T (2017) Two

Diverging Roads: A Semantic

Network Analysis of Chinese Social

Connection ("Guanxi") on Twitter.

Front. Digit. Humanit. 4:11.

doi: 10.3389/fdigh.2017.00011

\section{Two Diverging Roads: A Semantic Network Analysis of Chinese Social Connection ("Guanxi”) on Twitter}

\author{
Pu Yan and Taha Yasseri* \\ Oxford Internet Institute, University of Oxford, Oxford, United Kingdom
}

Guanxi, roughly translated as "social connection," is a term commonly used in the Chinese language. In this study, we employed a linguistic approach to explore popular discourses on guanxi. Although sharing the same Confucian roots, Chinese communities inside and outside Mainland China have undergone different historical trajectories. Hence, we took a comparative approach to examine guanxi in Mainland China and in Taiwan, Hong Kong, and Macau (TW-HK-M). Comparing guanxi discourses in two Chinese societies aim at revealing the divergence of guanxi culture. The data for this research were collected on Twitter over a three-week period by searching tweets containing guanxi written in simplified Chinese characters (关系) and in traditional Chinese characters (關係). After building, visualizing, and conducting community detection on both semantic networks, two guanxi discourses were then compared in terms of their major concept sub-communities. This study aims at addressing two questions: Has the meaning of guanxi transformed in contemporary Chinese societies? And how do different socio-economic configurations affect the practice of guanxi? Results suggest that guanxi in interpersonal relationships has adapted to a new family structure in both Chinese societies. In addition, the practice of guanxi in business varies in Mainland China and in TW-HK-M. Furthermore, an extended domain was identified where guanxi is used in a macro-level discussion of state relations. Network representations of the guanxi discourses enabled reification of the concept and shed lights on the understanding of social connections and social orders in contemporary China.

Keywords: Guanxi, China, twitter, semantic network analysis, text mining

\section{INTRODUCTION}

Guanxi is one of the key concepts scholars often use to describe Chinese societal features. It is the Romanization (pinyin) spelling of the Chinese character “关系” (in simplified Chinese) or “關係” (in traditional Chinese). It can be translated as "social connections" or "personal relationships." However, in Chinese language, the word entails much richer meanings than social connections, and is bound to notions such as obligation and loyalty to ascribed social groups. As specified by the Oxford Dictionary of English (2010), guanxi is "the relationship that facilitates business and other dealings." This definition emphasizes the functional role of guanxi in Chinese interpersonal relationships, but oversimplifies the complexities of guanxi connection and the art of manipulating social connections in contemporary Chinese culture. For example, La guanxi (拉关系), can 
be translated literarily as "to pull guanxi," describes the process of cultivating useful guanxi in exchange for favors. Zou houmen (走后门), meaning "going through the back door," is to obtain public resources from unofficial and personal channels. This expression is often used to describe the lack of fairness or justice in the allocation of public goods. The art of guanxi operates in a complex guanxiwang (关系网), which stands for one's guanxi network. Guanxi relations sometimes refer to an exclusive and yet politically influential social clique that shares similar guanxi ties.

Guanxi relations sometimes refer to an exclusive and yet politically influential social clique that shares similar guanxi ties. One recent example of the guanxi network in politics comes from China's continuing struggle against corruption and conspiracy. A group of government officials were indicted for corruption earlier this year. According to reports on Chinese state media, this network was established among tongxiang (同乡), people from the same hometown, forming a "protective umbrella" to cover up bribery and embezzlement, leading to a "systematic corruption" (Yi, 2014).

Today, Confucian culture still exists in Chinese societies around the world, including Mainland China, Taiwan, Hong Kong, Macau, and overseas Chinese communities (Jensen, 1997; Barmé, 2000). Guanxi culture, the social norms extended from traditional Confucian teaching, still exists in contemporary Chinese societies in the Mainland and in the greater Chinese regions, including Taiwan, Hong Kong, and Macau (TW-HK-M). However, these societies have gradually separated into distinct societies since in 1950s (Lin and Ho, 2009).

In Mainland China, Chinese traditional ethics and moral principles were first criticized and revolutionized with the establishment of People's Republic of China in 1949 and the Cultural Revolution from 1960s to 1970s. The ideological revolution was reflected in the Party's avocation of simplified Chinese (jiantizi 简体字) in formal printing and writing. However, the post-Mao era has seen the decline of Marxism and the revival of traditional values culture (Bell, 2010). The political rhetoric and the social orders that were valued in Confucianism, such as loyalty, family obligations, harmony, and concerns for others, have been once again emphasized in official and mainstream ideology.

Meanwhile, the greater Chinese communities outside Mainland China (for example, TW-HK-M) demonstrate distinct socio-economic and cultural features due to having had different historical trajectories. The democratization of Taiwan took place in 1980s and 1990s, which encouraged the public to participate in the political system and diversified the ideological system in Taiwan. As former colonies of Britain and Portugal, Hong Kong and Macau had been exposed to foreign cultures and ethics throughout their colonial history. Yet, Chinese culture and traditions still have an impact on the ethical and moral rules in Hong Kong and Macau (Wong, 1986). TW-HK-M did not adopt simplified Chinese, thus, traditional Chinese still dominates both the informal and formal writing systems. As Chinese societies adopt modern values, questions have been raised within academia on whether or not Chinese traditional culture still has profound influence on Chinese contemporary interpersonal relationships, to what extend it has adapted to social changes that come with Chinese modernization, and how it has diverged in Chinese communities that have demonstrated different socio-economic backgrounds.

\section{LITERATURE REVIEW}

\section{Conceptualizing Guanxi}

Early scholars studying guanxi culture traced its roots back to Chinese social structure. Chinese sociologist, Fei Xiaotong summarized the Chinese organizational principle into a "different mode of association" (chaxugeju, 差序格局) (Fei, 1992, p. 71), which resembles ripples spreading from the center of a body of water when a stone has been thrown into it. Social connections in China are non-equivalent and rely strongly on family ethics and kinship positions. Western social structures, in his opinion, have equivalent social connections and are constituted by autonomous groups and memberships. Fei's observation of Chinese social structure echoes the words of Max Weber. Weber noticed that behind that Chinese rational ethics were the principles of moral laws, which constitute a "complex of useful and particular traits" (Weber, 1964, p. 235). Chinese characteristic social patterning could also be attributed to the ethical system in Confucian teachings in which the fundamental traits in personal relationships are summarized into five basic ethics (Wu Lun 伦) (Liang, 1987). The similar patterning of family to non-family relationships also appears in Chinese five lun, which constitutes the basic social order within Chinese society (King, 1985).

Recent scholars have considered guanxi culture from a micro and interpersonal perspective. Empirical researches taking this perspective proved the importance of kinship system in Chinese guanxi culture. Jacobs (1979), p. 237, defined guanxi as "particularistic ties," which consists of ascriptive ties, such as family members or people from the same native place. Family and extended family ties are also the foundation and starting point of establishing other types of guanxi connections (Cohen, 1970; Baker, 1979). They sometime bridge the family ties with nonascriptive ties and forms a sense of intimacy beyond the realm of immediate family. Jankowiak (2008) found the phenomenon where individuals address unfamiliar friends as family members, such as sisters or uncles, in order to establish an intimate and useful connection.

Ethnographic research found that guanxi is often associated with sentiments (renqing, ganqing), face (mianzi), gifts (liwu), or favors; it is also deliberately maintained, cultivated, and even manipulated to facilitate other social activities (Hwang, 1987; Yang, 1994; Yan, 1996; Kipnis, 1997; Smart, 1999). These studies on guanxi practice vividly describe the guanxi dynamism.

As a word frequently used to describe social connections, guanxi is often compared with social network in the Western academia. Some scholars considered guanxi different from social network (King, 1985, 1991), while empirical research on guanxi suggested that guanxi practices could not be fully interpreted using the framework of social network, and thus guanxi has certain features that make it essentially Chinese (Burt, 1992, 2002; Bian, 1994; Bian and Ang, 1997; Xiao and Tsui, 2007). Another group of scholars disagreed with the uniqueness and Chineseness of guanxi (Lin, 2001; Wellman, 2001; Wellman et al., 2002). They 
tried to incorporated guanxi culture within a larger conceptual framework of social network. Nevertheless, they still acknowledge the cultural influence of guanxi in Chinese societies.

\section{Functional Practices of Guanxi in Business and Politics}

Studies conducted in Mainland China highlighted guanxi as a source of informal political power besides formal bureaucratic power, and in some cases even "defuse and subvert the elaborate regulations and restrictions" (Yang, 1994, p. 320). The administration "governed by human relationships" (Pye, 1992, p. 29) hampered Chinese government credibility in the Mainland, and has still exist in Chinese contemporary political system (Gold, 1986; Bian, 2002; Tsai, 2007).

Market economies in both Mainland China and TW-HK-M have prospered since the mid-1990s. Researchers observed a pragmatic practice of business guanxi in both Chinese societies. Studies on Chinese family companies located in both Mainland and other Chinese communities have found that family businesses often demonstrated nepotism and paternalism characteristics (Cohen, 1970; Wong, 1985). It is sometimes used as a business strategy to provide informal support and protections, and is utilized to raise venture capital (Xin and Pearce, 1996; Luo, 1997; Hamilton, 1998; Hsing, 1998; Wank, 1999).

However, mainland Chinese government plays a relatively strong role in the market economy. Study showed that business guanxi in the Mainland has been intentionally manipulated to establish connections with government officials in order to gain "back door access" in a state-dominated economy (Wank, 1999).

Turning to the twenty-first century, Chinese society in Mainland has moved toward a new model that demonstrates a combination of political socialism and economic capitalism. TW-HK-M, meanwhile, share closer ties with the world economy. Under such circumstances, has guanxi, or social connections in China, co-evolved with other societal changes?

Some scholars see guanxi as the cultural consequences of the ancient Chinese social structure. Guanxi culture is thought to be challenged by two forces: one from political rationalization and another from the influence of market economy.

Political rationalization and bureaucracy are believed to be an important factor accounting for the contemporary transformation of guanxi culture. Potter (2002), p. 183, argued that traditional Chinese guanxi will work as "a complement to rather than substitute for formal institutions" in the face of China's preceding legal reforms. Guthrie regarded guanxi as an "institutionally defined system" (Guthrie, 1998, p. 255) that could be shaped by the evolving political regime.

Chinese economic reform and the increasing influence of the market mechanisms are believed to be another driving force of the transformation of guanxi. For example, Yang (1994) speculated that abusive gift economy between government and market might gradually diminish with the market gradually replacing the state in resource distribution. Other researchers also documented the decline of cadre privilege (Walder, 1995) and the weakening of guanxi between officials and entrepreneurs ( $\mathrm{Ma}$ and Cheng, 2010) with institutional changes in market-oriented reforms.

\section{Research Questions}

As reviewed above, extensive research has contributed to the conceptualization of guanxi, and has examined the practice and transformation of guanxi culture. However, there remain two gaps in the literature: First, existing empirical research was mainly conducted during the early stages of Chinese reform in 1990s, this was when China was still a largely socialist economy. As Chinese societies are undergoing dramatic social, economic, and political changes, it is important to refine our understanding of guanxi in topics such as interpersonal relationships, informal politics, and business network in contemporary Chinese society. Second, in many of the works on guanxi, the concept is often traced back to its Confucian root. However, these societies have followed divergent historical paths and developed different political and economic systems. Thus, it is important to be aware of the differences between Confucian societies inside and outside of Mainland China.

Based on the gaps identified in the literature, this study explores the following two questions:

RQ 1: Against the background of political rationalization and economic reform, has the interpretation of guanxi changed in contemporary popular discourses?

RQ 2: When compared Mainland China to TW-HK-M, to what extent does guanxi adapt to different economic, social, and political environments?

Unlike previous studies of guanxi, this study takes a unique approach to examining contemporary guanxi culture. Data come from everyday discourses on social media. Text data of guanxi discourses in this research were collected from Twitter, which is the only popular microblogging site that has users from both Mainland and the greater Chinese communities, providing an ideal public arena for a comparative analysis of two Chinese popular discourses.

This type of evidence of how users talk about guanxi, rather than how they respond to surveys or what can be observed by scholars, reveals a much more diversified interpretation of guanxi than inspecting it within a particular social activity or contextualizing it within a specific community. As Kipnis (1996) argued, analyzing language surrounding guanxi can explore the richness of guanxi culture without over-generalizing the concept beyond its meanings.

\section{METHODS}

\section{Data}

Data in this research were collected from Twitter's Search API. ${ }^{1}$ The keywords in the search queries were simplified Chinese guanxi character (“关系”) and traditional Chinese guanxi character (“關係”). Keyword search queries for recent tweets were sent every day over a period of 3 weeks from May 12th to June 1st,

${ }^{1}$ The returned result type was set to be "recent" tweets. According to Twitter's official documentation, returned results are likely to be incomplete. See: https:// dev.twitter.com/rest/public/search 
2015. After combining the results and deleting duplicate tweets, ${ }^{2}$ there were 18,833 distinct tweets containing simplified Chinese guanxi and 9,572 distinct tweets containing traditional Chinese guanxi.

To justify our use of different written forms of guanxi as indicative of Chinese societies in different regions, we further compared the geological distributions of users in the two sets of tweets. This research used the different written forms of guanxi as proxies for two guanxi cultures. Location information (where available) was extracted from the metadata of all tweets, and was used for the comparison of the geographic distribution of users tweeting in simplified Chinese and in traditional Chinese. In this research, user time zone is chosen as the main indicator of locations. The distribution of user time zone suggests that language does indicate different locations. About $31.5 \%$ of tweets containing the simplified Chinese character guanxi were sent by users located in Mainland China, by contrast, the percentage of users located in Mainland China was only $17.91 \%$ in traditional Chinese tweets. A large percentage of users tweeting the traditional Chinese guanxi were located in TW-HK-M. Therefore, the user language, either simplified Chinese or traditional Chinese, overlaps with the regions in which the users are located. Noticing that $2.24 \%$ of simplified Chinese tweets were sent by users from Singapore and Malaysia, these tweets were deleted to enable comparison between Mainland China and TW-HK-M China. The final dataset contained 11,417 tweets about simplified Chinese guanxi and 9,572 tweets about traditional Chinese guanxi.

The two corpora in this research were organized and cleaned in three steps: punctuation filtering, word segmentation, and part-of-speech tagging and filtering. In the first step, raw texts in simplified Chinese and in traditional Chinese were aggregated separately by extracting tweet text from the dataset, and were processed to filter punctuations, emoji and other symbols. Then a Python module for Chinese word segmentation and part-ofspeech tagging, Jieba, ${ }^{3}$ was utilized to segment words in each sentence in both corpora. ${ }^{4,5}$ After tokenizing, the corpora consist only space-spliced words. Not all words are necessary for understanding the context of sentences (Jurafsky and Martin, 2014). By denoting all words in both corpora with their according partof-speech, we only keep words that are semantically meaningful, which includes nouns, verbs, adjectives, and adverbs.

\section{Semantic Network Analysis Word Cooccurrence}

In understanding word senses, one group of linguists suggested that approaching word meaning via its relationship with other

\footnotetext{
${ }^{2}$ Each tweet has a unique id ("id_str" in every status object), which was used as filter to delete repeated tweets in original dataset.

${ }^{3}$ GitHub page of Jieba. https://github.com/fxsjy/jieba

${ }^{4} \mathrm{An}$ alternative Chinese language segmentation software is NLPIR-ICTCLAS (http://www.nlpir.org/?action-viewnews-itemid-323). The two modules have similar Chinese word segmentation functions but Jieba has a dictionary that has better support for traditional Chinese characters (https:/github.com/fxsjy/jieba/ raw/master/extra_dict/dict.txt.big).

${ }^{5}$ Chinese natural language is written in a sentence without space, and thus splitting Chinese sentences is based on existing knowledge (pre-installed lexicon) of the common expressions.
}

words in the same sentence, taking a structuralism perspective (Firth, 1957; Evans, 2005; Saussure, 2011). To structuralize language in concrete forms, semantic network was proposed by applied linguists in the field of computer science (Quillian, 1963; Collins and Quillian, 1969).

As with other types of networks, semantic networks consist of vertexes and edges. Vertexes, or nodes, are concepts; edges can either be constructed by existing paradigmatic knowledge of linguistic relationships such as thesaurus (Kozima and Furugori, 1993; Fellbaum, 1998), or by the totality of structural relationships, such as cooccurrence (Danowski, 1993; Freeman and Barnett, 1994; Doerfel, 1998). By interpreting the structural features of the semantic network of a keyword, social science researchers are able to explore the contexts in which the keyword is discussed and understood in public discourses (Yuan et al., 2013).

In this study, we used word cooccurrence to construct the semantic network. As defined by Freeman and Barnett (1994), the links in a semantic network are the co-presence frequency of a pair of concepts in a given slicing window of the text. The slicing window in this study was set to be three words. ${ }^{6}$ To count the cooccurrence of word pairs and the frequency of each word, we used WORDij, ${ }^{7}$ a content analysis tool developed by Danowski (2013).

\section{Measuring Associations}

The association of each word pair $x$ and $y$ can be measured by their cooccurrence frequency. However, words in natural language are distributed following the power law (Jurafsky and Martin, 2014). Highly associated word pairs denoted by cooccurrence frequency, therefore, are likely to co-locate due to chances rather than semantically meaningful connections. For this reason, it is important to use a different measurement, one that can measure the likelihood that the target word pair $(x, y)$ co-occurred by chance irrespective of the frequency of the words. One such measurement using the ratio of observed occurrence and the expected probability of occurrence if two words appeared independently was proposed by Church and Hanks (1990), and is called pointwise mutual information (PMI):

$$
\operatorname{PMI}(x, y)=\log _{2} \frac{P(x, y)}{P(x) \times P(y)},
$$

where $P(x)$ and $P(y)$ are words' counts in the corpus, normalized by $N$, the size of the corpus. $P(x) \times P(y)$ measures the likelihood that $x$ and $y$ would co-occur in the same corpus if they were independent. $P(x, y)$ is the joint probability of $x$ and $y$ observed to be co-located in a window of $\mathrm{w}$ consecutive words.

Using PMI as a measurement of words association takes into account the scenarios in which two words only locate within the slicing window by chance. However, it has two drawbacks as a cooccurrence statistic. First, the denominator $P(x) \times P(y)$ could be extremely small for very rare words, making low frequency word combination scores disproportionately high, which would

${ }^{6}$ For the aim of conceptualizing guanxi, a smaller slicing window for identifying fixed expressions is preferred. (Church and Hanks, 1990).

${ }^{7}$ WORDij: http://www.content-analysis.de/2010/09/24/wordij.html 
interfere with detecting more meaningful and commonly used word pairs. Second, there is a lack of an upper bound for PMI value, making it practically difficult to define a high PMI score. To solve these two problems, Bouma (2009) devised a method to normalize PMI, which controls the influence of rare words and defines an upper boundary. The normalized measure, nPMI, is defined as:

$$
\operatorname{nPMI}(x, y)=\frac{\operatorname{PMI}(x, y)}{-\log _{2}(\mathrm{P}(x, y))} .
$$

In this research, the nPMI scores of all the word pairs were used as the weight of the edge between the two nodes in the semantic network.

\section{Visualizing and Interpreting Semantic Network}

After calculating the nPMI scores for all the word pairs in the simplified Chinese and traditional Chinese corpora, edges (weighted by nPMI score) and nodes (distinct words) can be visualized in two semantic networks: one in simplified Chinese and the other in traditional Chinese. Both networks were further filtered to exclude rare words and edges with lower nPMI values.
First, we filtered out words with very small frequencies; words that appeared three times or less in the simplified Chinese and only once in the traditional Chinese corpus.

Second, when choosing a threshold for significant word pairs, we used a percentile threshold for determining the most relevant word associations. ${ }^{8}$ The major consideration in choosing a threshold is not whether the nPMI value is statistically significant, but whether it is practically important for interpretations. Based on qualitative comparison of different percentile thresholds, we applied a threshold of the thirtieth percentile of sorted nPMI scores, which was 0.1955 for the simplified Chinese corpus and 0.2546 for the traditional Chinese corpus.

${ }^{8}$ Another method to identify significant edges is to shuffle the nodes (words), shuffle the network while remain the node degrees, and rewire nodes randomly with each other. By calculating t-value, a p-value can be found using Student's t-distribution. If $\mathrm{p}$-value is less than the conventional threshold for statistical significance, 0.05 , then the null hypothesis (two words are independent) is rejected and the alternative hypothesis (they are associated semantically) is accepted (see Newman et al., 2002)

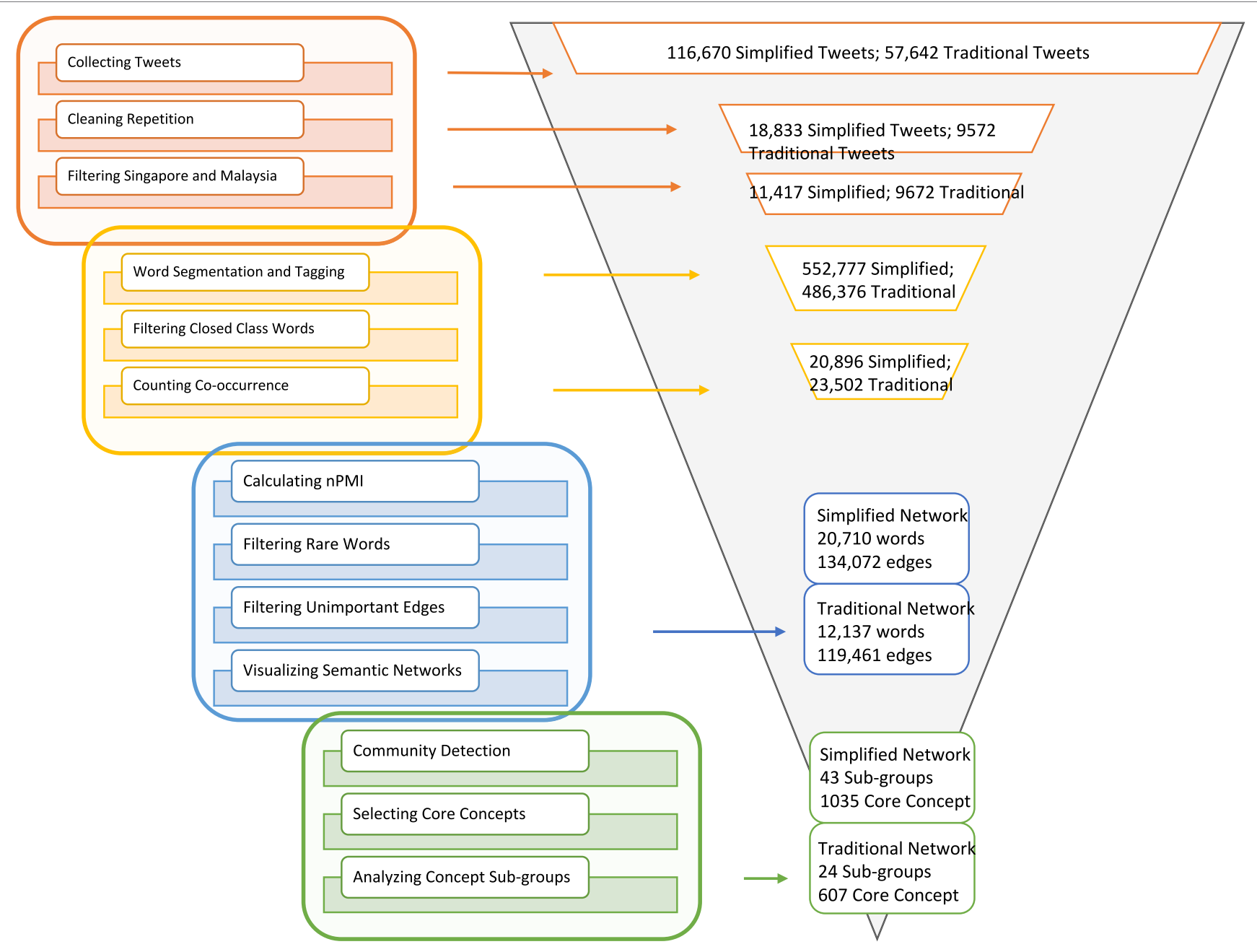

FIGURE 1 | Methodology and data cleaning 


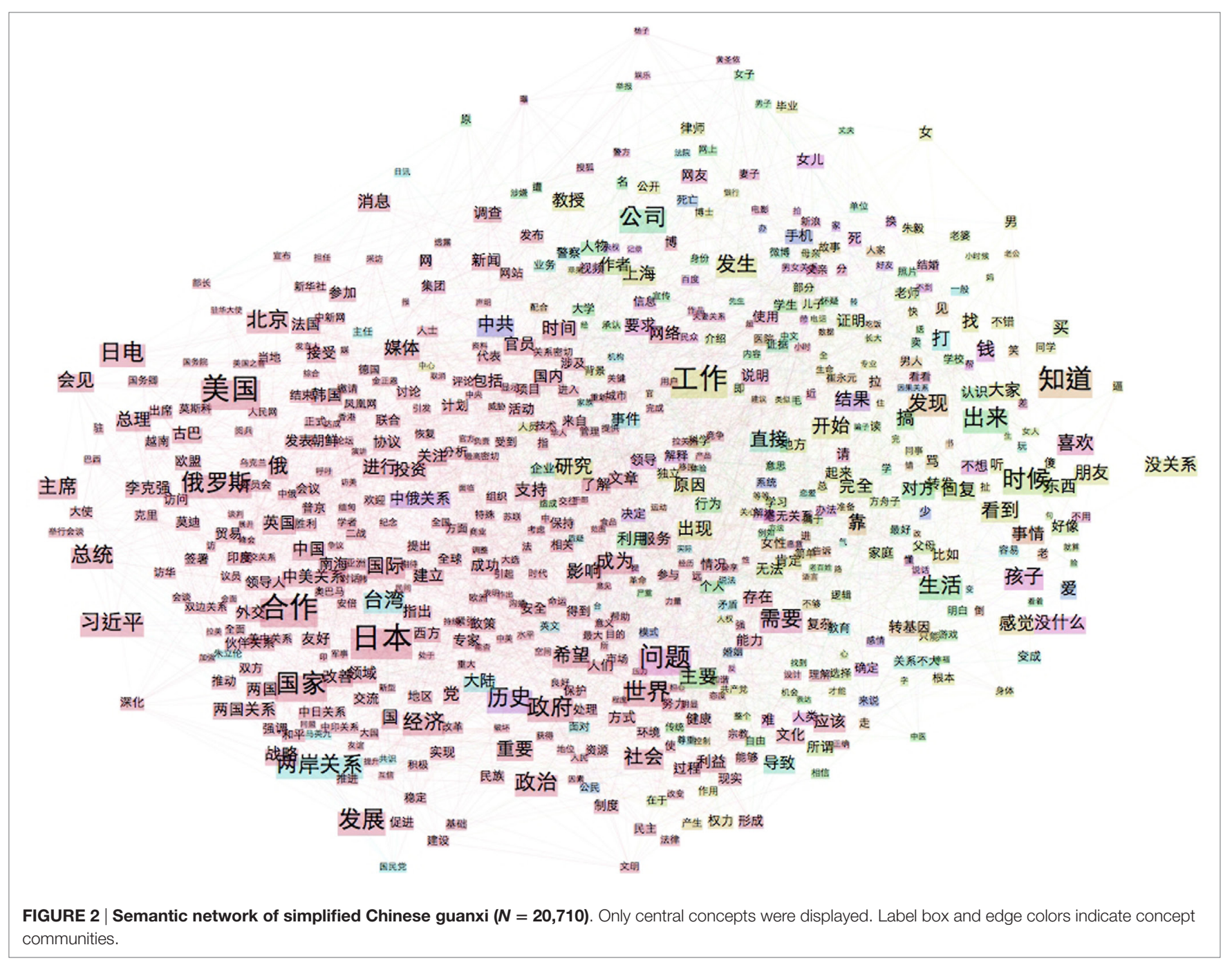

Two semantic networks consisting of edges with weights (nPMI scores) exceeding the threshold values could now be constructed based on the filtered nPMI scores. After removing rare words and filtering unimportant word pairs, there were 20,710 words and 134,072 edges in the simplified Chinese semantic network and 12,137 words and 119,461 edges in the traditional Chinese semantic network.

The semantic network of guanxi in simplified Chinese and in traditional Chinese was displayed separately, each node represents a word from guanxi corpora. Node size indicating the node strength, which is the sum of weights attached to edges belonging to a node (Barrat et al., 2004). Edges are undirected and weighted. Two semantic networks were visualized using network analysis tool: Gephi (Bastian et al., 2009), displayed by applying Force Atlas 2 algorithm (Jacomy et al., 2014). Word pairs connected by edges with higher association values (nPMI scores) are attracted proportionally closer than others.

Semantic networks contain a large amount of concepts and concept relations. To categorize concepts, community detections were applied on both guanxi semantic networks using modularity partition algorithm in Gephi (Newman, 2006). After partitioning, the simplified Chinese semantic network of guanxi was divided into 43 communities, with modularity score $=0.431$; the Traditional semantic network was partitioned into 24 communities, with a modularity score of $0.339 .{ }^{9}$

Themes of each sub-community were summarized by the central concepts, which were defined as the top $5 \%$ of nodes ranked by their node strength in descending order. Figures $\mathbf{2}$ and $\mathbf{3}$ show the clustered networks of simplified Chinese guanxi and traditional Chinese guanxi. Figure 1 summarizes the methodology of this research using a flow chart.

\section{RESULTS}

By comparing the concept sub-communities of the two guanxi semantic networks, we found that although the two discourse

${ }^{9}$ During the process of modularity optimization, both modularity scores were highest when resolutions were 1.0. Modularity scores were used to compare between possible partition results in the same network, not for comparing between two networks. The resolutions were set as 1.0 in Gephi for both networks. 


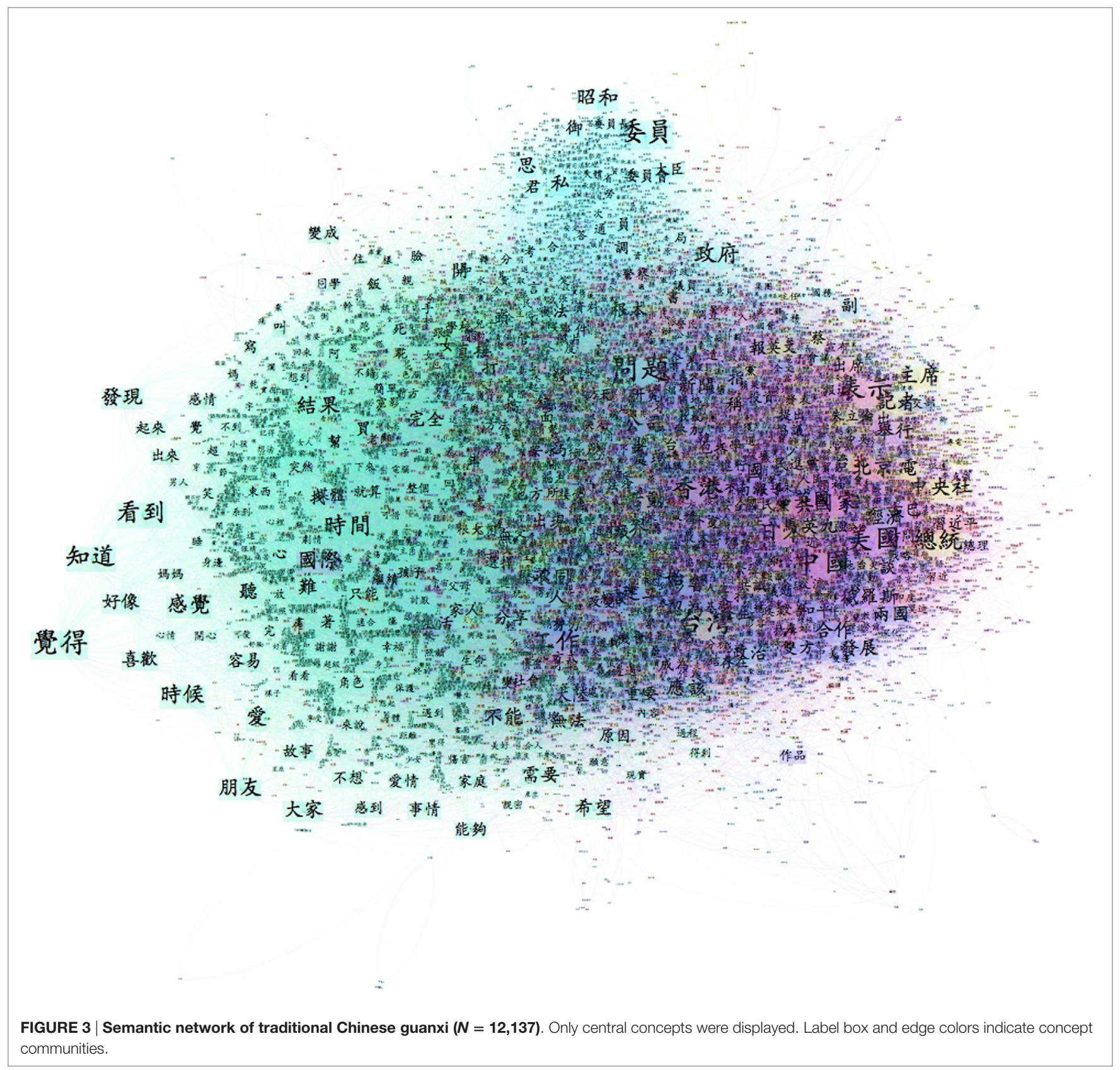

networks share similar themes, including interpersonal relationships, business-political networks, and state relations. However, they demonstrated different interpretations within these topics.

\section{Guanxi in Interpersonal Relationships}

As explained previously, guanxi consists of social norms and traditions relating to interpersonal connections. Through examining the simplified and traditional guanxi semantic networks, it can be seen that they both have one or several sub-groups concerning interpersonal relations. However, guanxi in the domain of interpersonal relationships have demonstrated different focuses in the two Chinese societies.

\section{Mainland: Intimacy and Traditions}

There are two concept communities in simplified Chinese semantic network related to interpersonal relationships. The first one ranks the third largest sub-community (see Figure 4), highlighting intimate guanxi; the second one is the fourth largest sub-community (see Figure 5) in the simplified Chinese network, with a focus on Chinese traditions.

Familism in traditional Chinese culture consists of members within an extended family. Particularly in rural China, the boundary of a family could be as broad as a lineage or a clan (King, 1991). However, as shown in Figure 4, the highest ranked concept community in family guanxi in simplified Chinese is more concerned with the nuclear family than it is with lineage. 


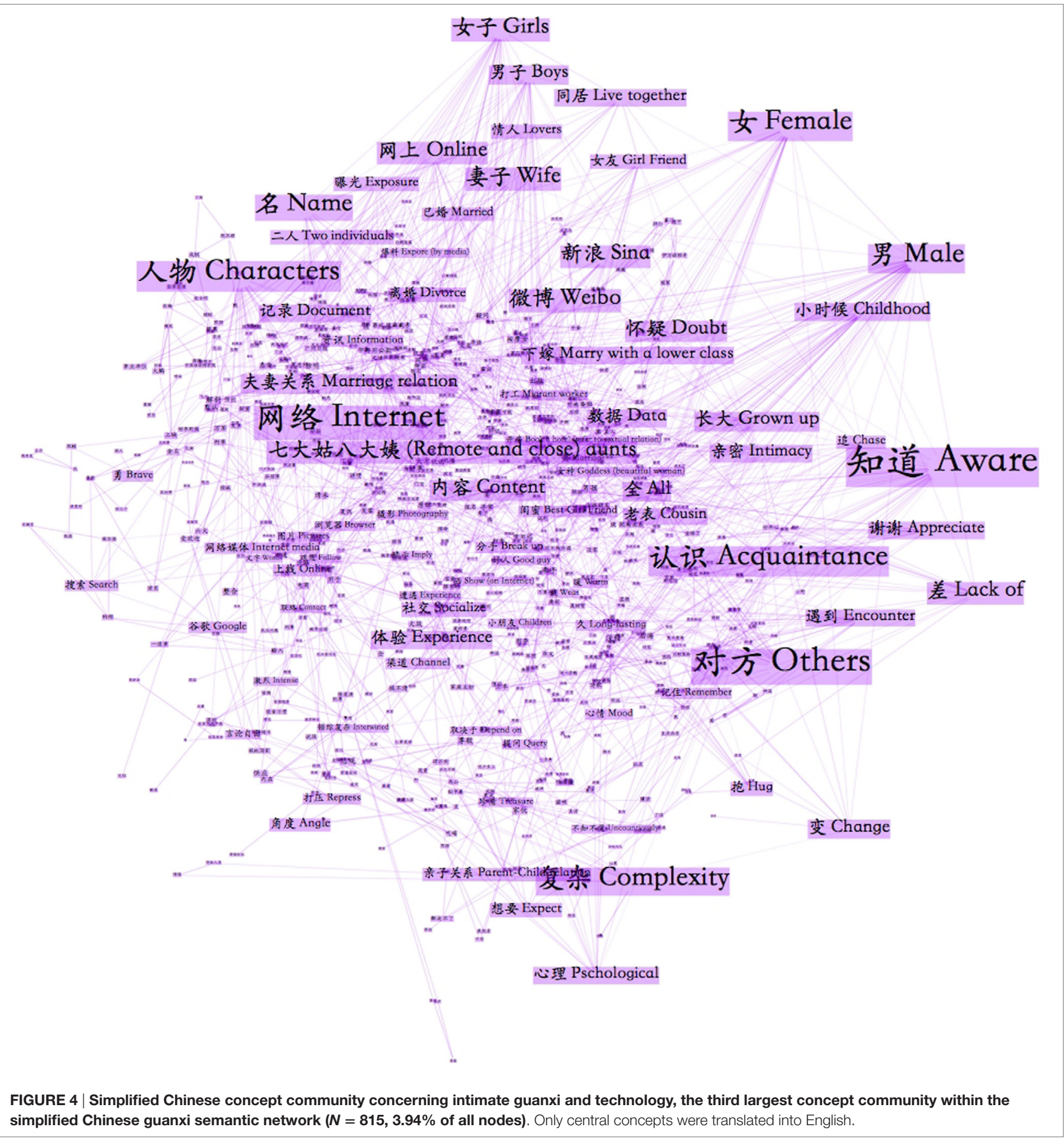

Concepts related to romance are emphasized by relationships such as “Marriage relations” (夫妻关系), “Lovers” (情人), and roles such as “Wife" (妻子) or “Girlfriend” (女友). The extended family retains its influence on individual through interfering with marriage. Interestingly, the influence of emerging digital technologies on modern intimate relationships is also reflected on the semantic network of guanxi in Mainland China: concepts such as “Online” (“网上”) and “Internet” (“网络”) are neighboring to concepts concerning intimate relationships such as "Intimacy" (“亲密”) in the semantic network. Social networking services such as “Weibo” (“微博”), a popular microblogging site in China, is also one of the central concepts in this semantic community. See Table 1 for the rank of node strength of the abovementioned central concepts in these sub-communities.

Concepts of guanxi as a tradition or cultural heritage belong to the fourth largest concept sub-community in the simplified 


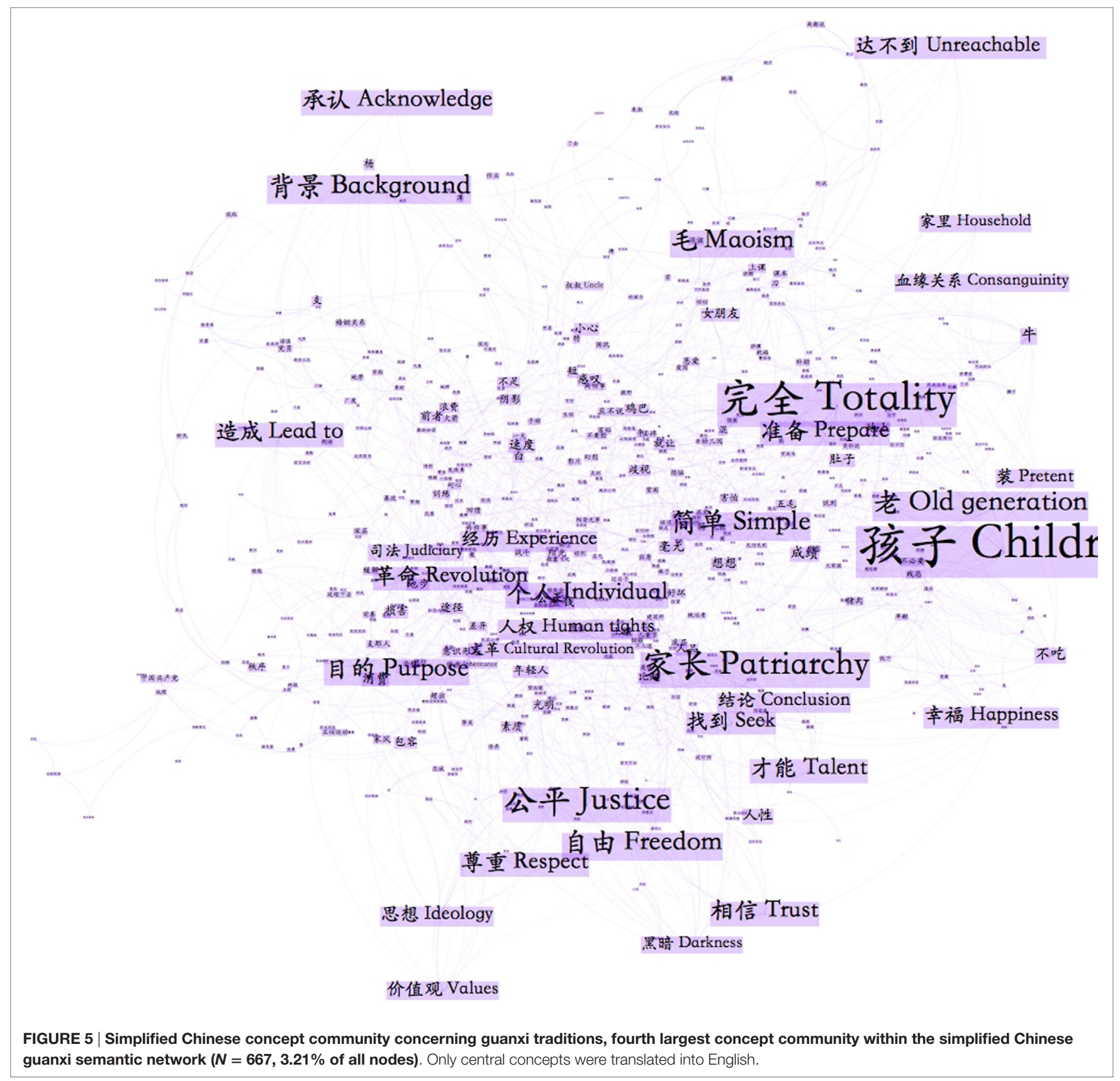

Chinese semantic network (displayed in Figure 5). In this community, feelings and social consequences of guanxi tradition were discussed. Originating from "lun" in Confucianism, the guanxi tradition is characterized by "Patriarchy” (“家长制”), which is also the node that has the highest node strength in this subcommunity. The concept "Patriarchy" is connected to "Children" (“孩子”) and “Value” (“价值观”), indicating an embedded attitude toward the next generation. In addition, the traditions are connected through attributive ties, especially by "Consanguinity" (“血缘关系”), which is the sharing of bloodlines.

There is, however, a bittersweet emotion regarding traditional guanxi that is embedded in Chinese family morals. Centered on the deeply rooted guanxi traditions, there is nostalgia for a harmonious household and concern about overall social equality. On one hand, nostalgia for the guanxi tradition is linked to harmonious family relationships and cohesive family structure. For example, emotions like “Happiness” (“幸福”) and a sense of “Trust” (“信任”) are all inherent characteristics of the guanxi tradition. On the other hand, after Mao's anti-tradition social movement from 1966 to 1976, the “Cultural Revolution” (“文革”) had challenged traditional values in urban and rural China tremendously, which is also reflected in this concept community via concepts such as “Revolution” (“革命”). With the Chinese modernization process, there are also negative attitudes toward 
traditional guanxi norms. One criticism of guanxi tradition is the over-emphasis on one's family “background” (“背景”). If used illegitimately to obtain private profits, guanxi might pose a threat to social “justice” (“公平”). See Table 2 for the rank of node strength of the abovementioned central concepts in these sub-communities.

\section{TW-HK-M: New Wine in Old Bottles}

Concepts regarding interpersonal relationships form the largest concept communities in the traditional Chinese semantic network. This ranking order suggests that discourses on guanxi are more often associated with social connections in TW-HK-M than they are in Mainland. The two Chinese communities also have varying emphasis on interpersonal relationships. As analyzed in the simplified Chinese network, intimate guanxi and guanxi heritage are heated topics in the domain of relationships. In the traditional Chinese guanxi network, however, central concepts are more general descriptions of social networks, with less debate on the traditions of Chinese family morals (see Figure 6).

Chinese users in TW-HK-M show a form of interpersonal guanxi that is closer to the modern concept of social connections in many Western societies. Traditional guanxi relations and the traditional moral requirements for the family are both missing from this sub-community.

This concept sub-group in traditional Chinese embraces a wide range of issues concerning interpersonal relations ranging from types of social relationships such as "Family" relations (“家庭”), “Schoolmates” (“同學”); to “Social roles” (“社會角色”) of individuals in these relations, including “Parents” (“父母”), “Wife” (“妻子”); and to emotions and feelings about relationships, for instance, “Love” (“爱情”), “Trust” (“信任”), “Intimacy” (“親密”), or “Dislike” (“討厭”). Although the types of guanxi in this community are diverse, which include weak ties such as “Friends” (“朋友”) and “Schoolmates” (“同學”), there is still more mentions of members in a nuclear family. However, there are still differentiations between close and general guanxi relationships. For example, the concept "Family" (“家庭”) is connected to “Life” (“生命”), “Intimate”(“親”), and “Protect”(“保護”), which indicates more responsibility and involvement in family relationships. See Table 3 for the rank of node strength of the abovementioned central concepts in these sub-communities.

\section{Guanxi in Two Market Economies}

As reviewed earlier, much research on the Mainland China and TW-HK-M markets has noticed the pervasiveness of guanxi practice in Chinese companies. Networks in this research also prove that guanxi in economic activities is an important topic in both societies, but business guanxi functions differently in the two contexts.

\section{Mainland China: Guanxi and Rent-Seeking Behaviors}

In one concept community of the simplified semantic network, guanxi is frequently associated with rent-seeking behaviors, through manipulating guanxi ties with government officials. Concepts in this domain cover both the major players in rentseeking processes and the corresponding social consequences of such practices. This concept sub-community on business-political guanxi in simplified Chinese is displayed in Figure 7.

Unlike what was observed in the early stages of Chinese economic reform (Yang, 1994) when guanxi was mainly used to acquire priority in the distribution of raw materials for production. In the contemporary Chinese economy, the abuse of power and position extends to the "Capital” (“资本”) and "Investing” (“投资”) processes. Industries referred to in this concept community ranged from primary or infrastructural industries to nontraditional or emerging industries such as “Technology” (“科技”) and “Finance" (“金融”). Regarding the soil in which the rampant corruption is embedded, the “Cliques" (“集团”) between “Local” (“地方”) officials and “Corporations” (“企业”) are all mentioned. The “Interest” (利益) of “Government officials” (“官员”) was particularly important under this topic. Consequently, there are also discussions on regulating and restricting guanxi practice in business. The violations of formal "Law" (“法”) and public “Investigation” (“调查”) have provoked “Reflection” (“检讨”) on the Chinese “Bureaucratic" system (“制度”) in order to ensure “Equality” (“平等”) in market competitions, providing equal opportunities for incorrupt competitors. The public discourses also appeal for laws that regulate practices of guanxi in politics and business: neighboring to the concept “Law” (“法律”) are concepts that calls for actions to ensure social justices, for example, to “Clarify” (“明确”) and “Adhere to” (“遵循”) regulations.

TABLE 1 | Rank of node strength of central concepts in the third largest sub-community of simplified guanxi semantic network: interpersonal guanxi.

\begin{tabular}{|c|c|c|}
\hline Central concept & Node strength & $\begin{array}{l}\text { Rank of node strength } \\
\text { in the sub-community }\end{array}$ \\
\hline "Marriage relations" (夫妻关系) & 22.735519722104 & 21 \\
\hline “Lovers" (情人) & 16.25607876 & 38 \\
\hline “Wife" (妻子) & 28.24200945 & 12 \\
\hline "Girlfriend" (女友) & 16.4118893295526 & 37 \\
\hline "Online" (“网上") & 26.8641610741615 & 16 \\
\hline “Internet” (“网络”) & 44.21232368052 & 3 \\
\hline “Intimacy” (“亲密”) & 20.63523827 & 26 \\
\hline “Weibo" (“微博”) & 28.2873573601245 & 11 \\
\hline
\end{tabular}

The total number of central concepts in this sub-community is 41 .

TABLE 2 | Rank of node strength of central concepts in the fourth largest sub-community of simplified guanxi semantic network: interpersonal guanxi.

\begin{tabular}{lcc}
\hline Central concept & Node strength & $\begin{array}{c}\text { Rank of node strength } \\
\text { in the sub-community }\end{array}$ \\
\hline "Patriarchy" (“家长制”) & 19.01765558 & 3 \\
"Children” (“孩子”) & 55.7005976 & 1 \\
"Value” (“价值观”) & 18.79995203 & 26 \\
"Consanguinity" (“血缘关系”) & 22.71009071 & 28 \\
"Happiness" (“幸福”) & 21.25359423 & 21 \\
"Trust” (“信任”) & 25.43865915 & 13 \\
"Cultural Revolution” (“文革”) & 16.02277347 & 33 \\
"Revolution” (“革命”) & 23.93021889 & 6 \\
"Background” (“背景”) & 29.80584311 & 4 \\
"Justice” (“公平”) & 19.17124559 & 6 \\
\hline
\end{tabular}

The total number of central concepts in this sub-community is 34 . 


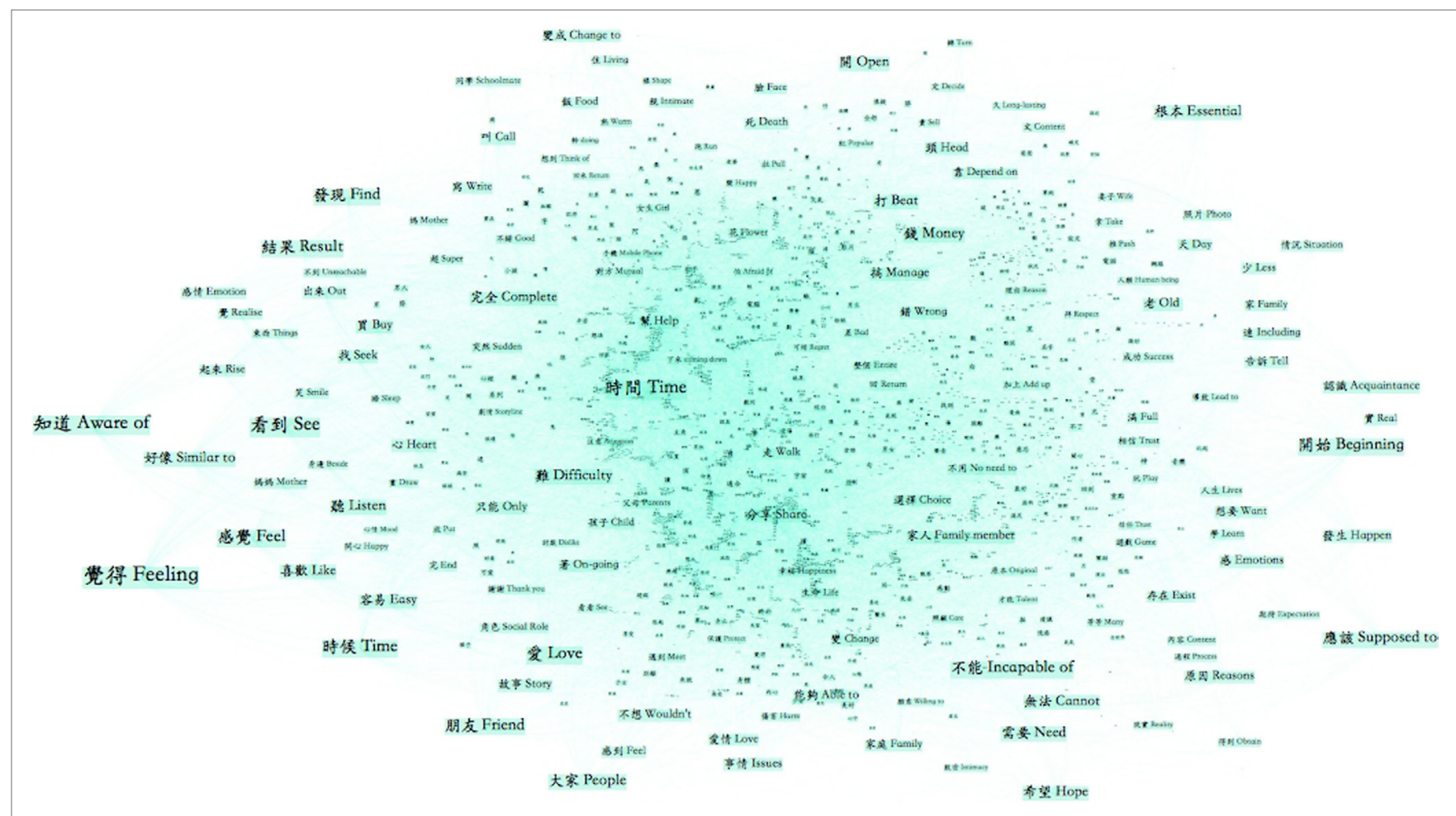

FIGURE 6 | Traditional Chinese concept community concerning interpersonal relationships. Largest concept community within the traditional Chinese guanxi semantic network ( $N=3,224,26.61 \%$ of all nodes). Only central concepts were translated into English.

See Table 4 for the rank of node strength of the abovementioned central concepts in these sub-communities.

\section{TW-HK-M: Business Network and Regulated Guanxi}

In traditional guanxi semantic network, topics on business guanxi locate in separated community with political guanxi. Such a separation is different what is observed in simplified guanxi semantic network of Mainland users.

The second largest concept community in the traditional Chinese semantic network consists of concepts related to business guanxi (see Figure 8). Unlike simplified Chinese business guanxi, this concept community tends to focus on guanxi in economic activities as a business strategy, which separates the market from government officials. “Enterprises” (“企業”) and “Companies" (“公司”) are major players in the business guanxi network. Guanxi in their business "Strategy" (“戰略”) is considered to be access to personal "Communications" (“溝通”) and as “Opportunities” (“機會”) and “Investment” (“投資”). Compared to enterprises in Mainland, who have to invest in establishing guanxi resources with government officials; guanxi in TW-HK-M is a form of human resource and an informal business strategy brought by and maintained through personal ties between business partners: neighboring to the concept "Guanxi Capitals" are “Influence” (“影響”), “Management” (“管理”), and is linked to "Individual" (“個人”) connections. See Table 5 for the rank of node strength of the abovementioned central concepts in these sub-communities.
Concepts of political guanxi are located in a different concept community in the traditional Chinese semantic network, ranking as the fourth largest concept community (see Figure 9). In this concept community, political guanxi is confined to the legislative, executive, and administrative divisions. Individuals who have political power are mentioned in a same political network, consisting of “Civil servant” (“公務員”), “Committee member” (“委員”), and “Member of Parliament” (“議員”). This concept community also demonstrates a clear separation between the "Private" (“私”) domain and the "Public" (“公”) domain, as well as highlighting “Regulation” (“制度”), and “Law” (“法”) as constraints of the political guanxi. See Table 6 for the rank of node strength of the abovementioned central concepts in these sub-communities.

Therefore, business guanxi in TW-HK-M is linked more closely to networks among personnel and less with governments. Political guanxi also raises alarms in these societies, but is restrained by written constitutions and formal laws.

\section{Guanxi in Power Relations}

Most scholarly writings on guanxi considered the concept from micro- and meso-levels, focusing on the role of guanxi in networking activities between individuals and organizations. However, community-clustering on both guanxi semantic networks captured a new context of using guanxi, which is in power dynamics between states.

Figures 10 and $\mathbf{1 1}$ display the largest sub-community of the simplified Chinese guanxi semantic network (see Table 7 for the rank of node strength of the abovementioned central concepts in 
TABLE 3 | Rank of node strength of central concepts in the largest sub-community of traditional guanxi semantic network: interpersonal guanxi.

\begin{tabular}{|c|c|c|c|c|c|}
\hline Central concept & Node strength & $\begin{array}{l}\text { Rank of node strength in the } \\
\text { sub-community }\end{array}$ & Central concept & Node strength & $\begin{array}{c}\text { Rank of node strength in the } \\
\text { sub-community }\end{array}$ \\
\hline “Family” (“家庭”) & 43.68824178 & 61 & “Friends” (“朋友”) & 63.68144655 & 11 \\
\hline "Schoolmates” (“同學”) & 35.89932814 & 90 & “Dislike” (“討厭”) & 28.45496404 & 152 \\
\hline "Social roles" (“社會角色”) & 38.75919664 & 78 & “Life” (“生命”) & 38.08616459 & 80 \\
\hline “Parents” (“父母”) & 34.85653216 & 97 & “Intimate”(“親”) & 35.3957012295722 & 95 \\
\hline "Wife” (“妻子”) & 33.01248613 & 107 & “Protect” (“保護”) & 28.20108119 & 155 \\
\hline “Love” (“爱情”) & 67.15074652 & 7 & “Intimacy” (“親密”) & 28.7050186693668 & 150 \\
\hline “Trust” (“信任”) & 35.86647654 & 91 & & & \\
\hline
\end{tabular}

The total number of central concepts in this sub-community is 161 .

\section{调查 Investigation}

\section{公司 Company}

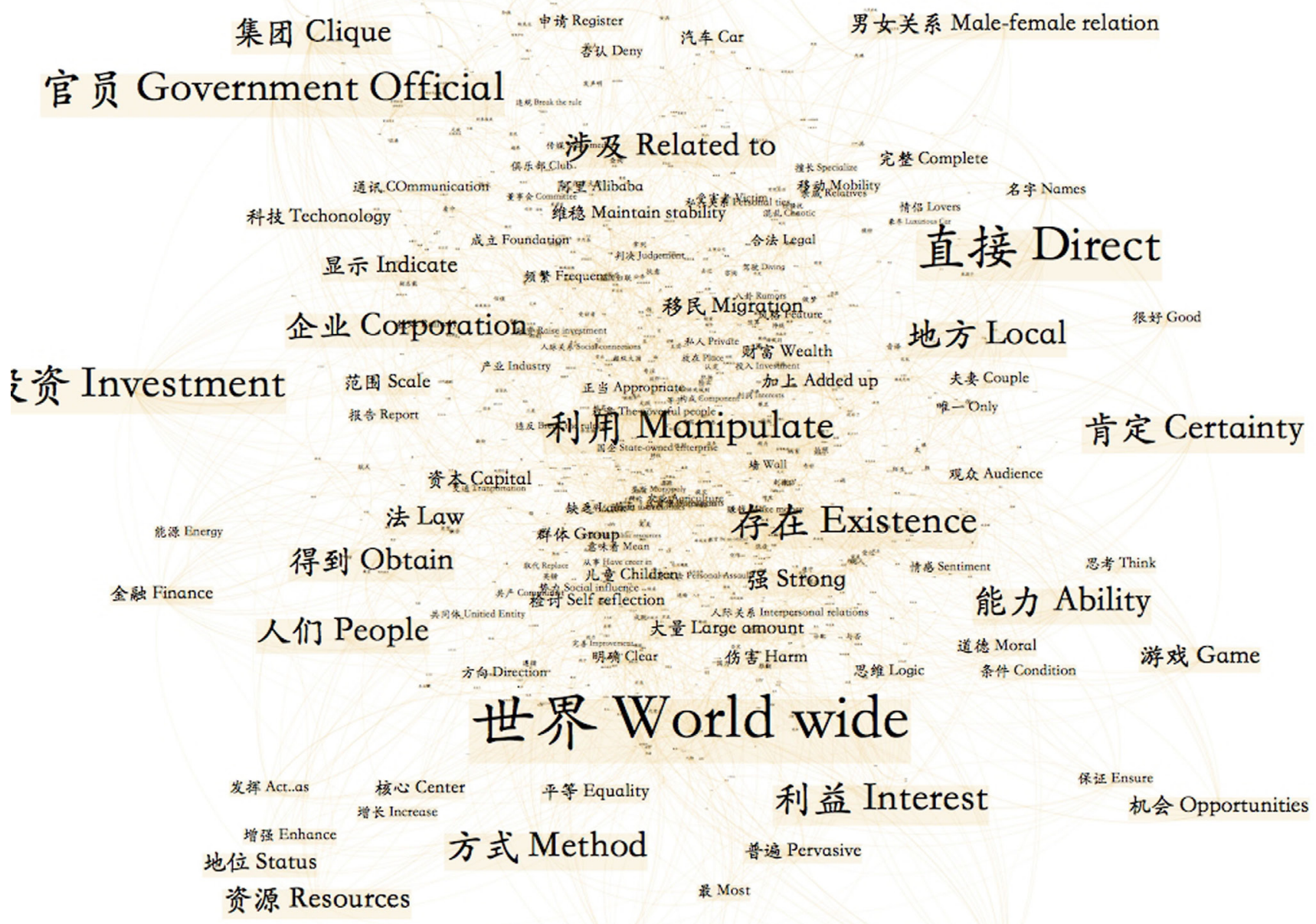

\section{制度 Bureaucracy}

$$
\text { 产生 Generate }
$$

\section{形成 Formation}

FIGURE 7 | Simplified Chinese concept community concerning business and government. Second largest concept community within the simplified Chinese guanxi semantic network ( $N=987,4.75 \%$ of all nodes). Only central concepts were translated into English. 
TABLE 4 | Rank of node strength of central concepts in the second largest sub-community of simplified guanxi semantic network: business-political guanxi.

\begin{tabular}{|c|c|c|c|c|c|}
\hline Central concept & Node strength & $\begin{array}{l}\text { Rank of node strength in the } \\
\text { sub-community }\end{array}$ & Central concept & Node strength & $\begin{array}{c}\text { Rank of node strength in the } \\
\text { sub-community }\end{array}$ \\
\hline “Capital” (“资本”) & 7.595787898 & 31 & "Corporations” (“企业”) & 34.78581253 & 17 \\
\hline “Investing” (“投资”) & 46.2482437 & 4 & “Law” (“法”) & 27.8758501 & 23 \\
\hline $\begin{array}{l}\text { "Government Officials” } \\
\text { (“政府官员”) }\end{array}$ & 44.66833891 & 5 & "Investigation” (“调查”) & 39.73360538 & 9 \\
\hline "Interest” (“利益”) & 41.57831243 & 8 & “Reflection” (“检讨”) & 8.10880509 & 45 \\
\hline “Manipulate” (“利用”) & 43.0961566 & 6 & “Bureaucratic” system (“制度”) & 35.3473607 & 16 \\
\hline “Technology” (“科技”) & 20.02016431 & 34 & "Equality” (“平等”) & 19.58096483 & 36 \\
\hline "Finance" (“金融”) & 19.44720884 & 38 & “Clarify” (“明确”) & 15.53840297 & 62 \\
\hline “Cliques" (“集团”) & 34.05836044 & 19 & “Adhere to" (“遵循”) & 7.582168639 & 136 \\
\hline “Local” (“地方”) & 36.82139555 & 13 & & & \\
\hline
\end{tabular}

The total number of central concepts in this sub-community is 45. Also note that "Clarify" and "Adhere to" are not central concepts, but they are included in this table because they are connected with the central concepts "Law" in the semantic network and thus mentioned in our analysis.

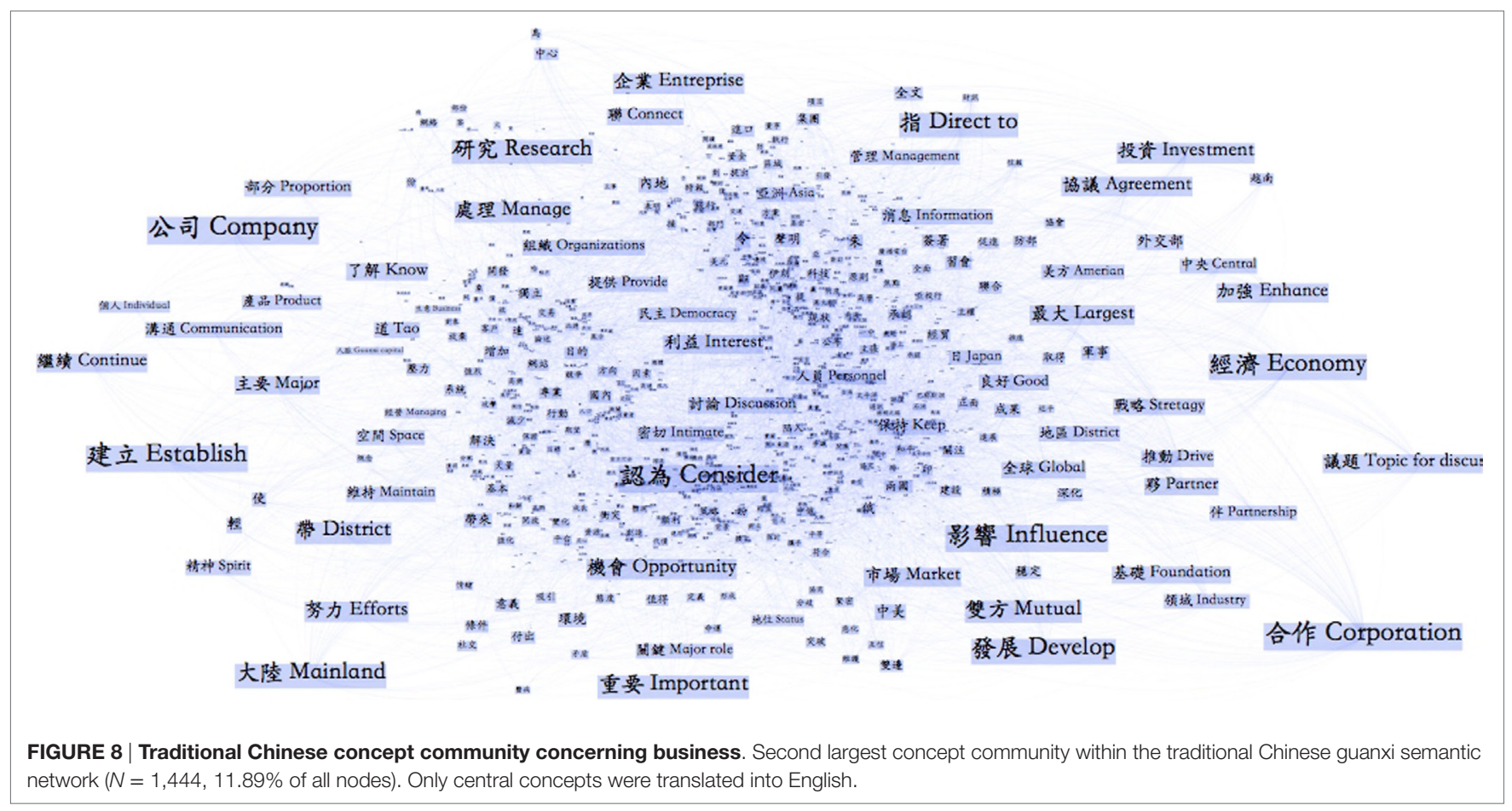

these sub-communities.) and the third largest sub-community of the traditional Chinese guanxi semantic network (see Table 8 for the rank of node strength of the abovementioned central concepts in these sub-communities.); both communities contain concepts describing relationships between states.

In simplified Chinese, most of the concepts of guanxi between states concerning diplomatic taxonomies [i.e., "Bilateral Relations” (“双边关系”) and “Diplomacy” (“外交”)] and country names [i.e., “Cuba” (“古巴”) and “Russia”(“俄罗斯”)]. Interestingly enough, it also demonstrates many diplomatic strategies borrowed from Chinese interpersonal social norms. For example, sentiments such as “Family" (家庭) and "Friendly" connections (“友好”), the terms for close ties, is mentioned in the domain of international relations. This finding of state relations in both discourses has two implications: First, it
TABLE 5 | Rank of node strength of central concepts in the second largest sub-community of traditional guanxi semantic network: business guanxi.

\begin{tabular}{|c|c|c|}
\hline Central concept & $\begin{array}{l}\text { Node } \\
\text { strength }\end{array}$ & $\begin{array}{l}\text { Rank of node strength } \\
\text { in the sub-community }\end{array}$ \\
\hline “Enterprises” (“企業”) & 45.21087343 & 16 \\
\hline “Companies” (“公司”) & 62.01969993 & 1 \\
\hline “Strategy” (“戰略”) & 36.61361367 & 33 \\
\hline “Communications”(“溝通”) & 34.88546649 & 40 \\
\hline "Strategy" ("人脈") & 36.61361367 & 33 \\
\hline “Opportunities” (“機會”) & 45.82440343 & 15 \\
\hline “Investment” (“投資”) & 44.88682291 & 18 \\
\hline “Influence” (“影響”) & 59.85411802 & 4 \\
\hline “Management” (“管理”) & 31.94695401 & 64 \\
\hline “Opportunity” (“機會”) & 45.82440343 & 15 \\
\hline
\end{tabular}

The total number of central concepts in this sub-community is 72 . 


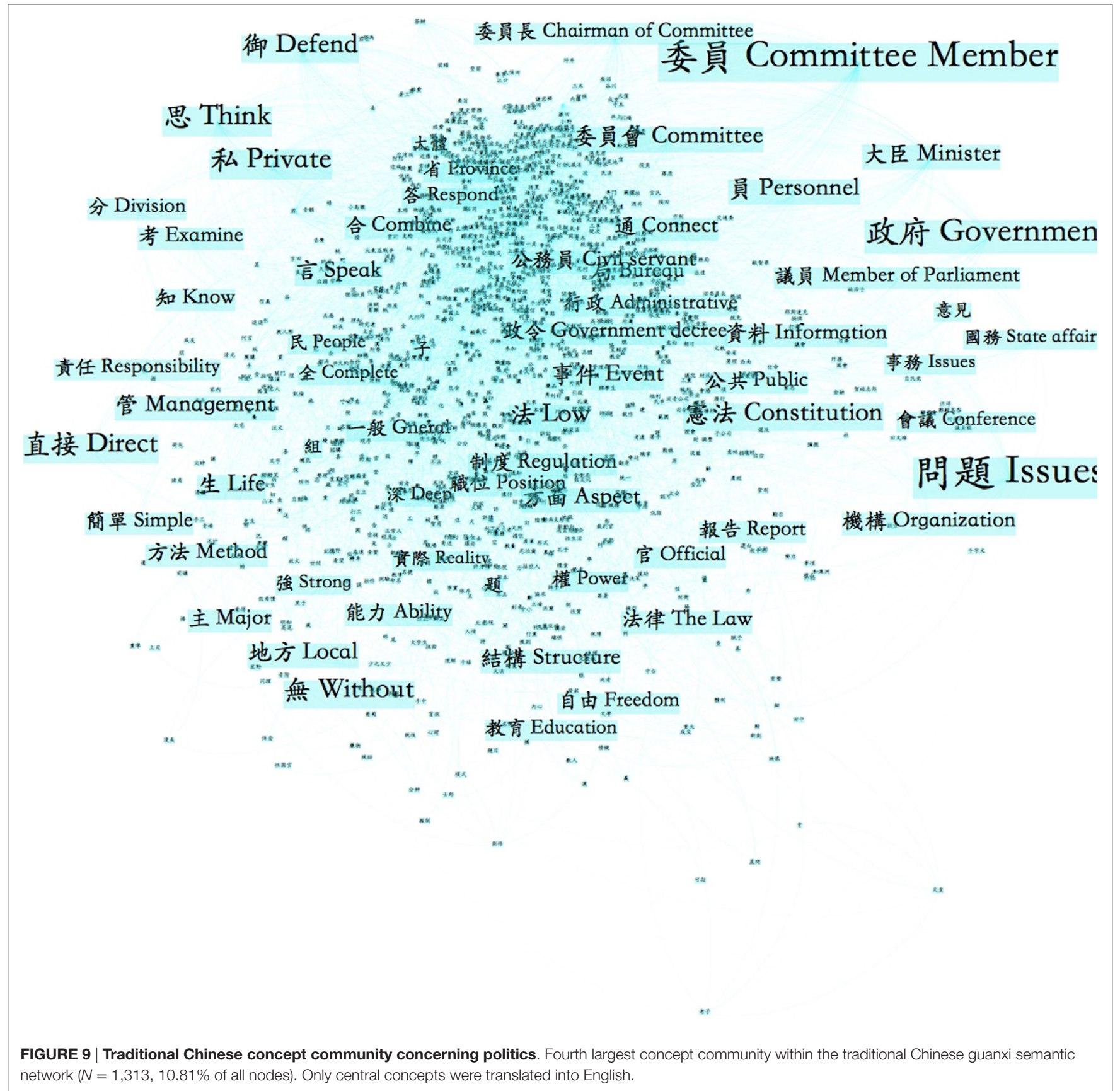

suggests that Chinese guanxi culture is also reflected in the state's foreign policies. This expands the realm of guanxi study to the state level, and to Chinese diplomatic relations with other countries. As highlighted by the personalized sentiments in this concept community, the promotion of Confucian values plays an important role in Chinese diplomatic strategy. Second, the fact that over $16 \%$ of all concepts in simplified Chinese guanxi semantics and $11 \%$ in traditional Chinese guanxi semantics reside within this state relation community also indicates that in both Mainland China and in TW-HK-M China, Twitter is used regularly as news following and sharing services. This is also proved by the appearance of newspaper and agency names such as “People’s Daily” (“人民网”) and “VOA” (“美国之音”) in the sub-community. In traditional Chinese guanxi semantic network, central concepts related to international relations such as “Diplomacy” (“外交”) and “National visit” (“訪問”) also appears, along with concepts concerning media report and news agencies, for example, “Report” (“報導”) and “Apple Daily” (“蘋果日報”).

\section{DISCUSSION}

This study uses guanxi discourses from social media to explore the transformation of guanxi culture in contemporary popular 
discourses. Table 9 provides an overview of the concept communities analyzed in this study. The largest four concept communities in each semantic network cover three major topics concerning interpersonal relationships, business guanxi, and state relations.

\begin{tabular}{|c|c|c|}
\hline Central concept & Node strength & $\begin{array}{l}\text { Rank of node strength } \\
\text { in the sub-community }\end{array}$ \\
\hline “Civil Servant” (“公務員”) & 39.00365302 & 27 \\
\hline “Committee Member” (“委員”) & 85.50669757 & 2 \\
\hline “Member of Parliament” (“議員”) & 36.48606274 & 38 \\
\hline "Private" (“私”) & 59.76781264 & 5 \\
\hline “Public” (“公”) & 37.02095327 & 36 \\
\hline “Regulation” (“制度”) & 38.37267345 & 30 \\
\hline “Law”(“法”) & 52.778667 & 10 \\
\hline
\end{tabular}

The total number of central concepts in this sub-community is 66 .

\section{Transformation of Family Values}

We found that in terms of interpersonal relationships, both Mainland and TW-HK-M China have demonstrated an emphasis concerning the nuclear family. However, concept communities on interpersonal relationships show that the significance of traditional lineage families and their associated morals are declining in both the Mainland and TW-HK-M.

Despite the transformation of the family structure reflected in guanxi discourses, in the simplified Chinese guanxi semantic network, special attention is still paid on the traditional values and morals in Mainland China. In the discussion of traditions, many concepts reflected negative attitudes toward the traditional system of hierarchy within the family and toward the overemphasis of family background.

This widespread doubt about traditional family guanxi within the simplified Chinese semantic network will be likely to result in a clash with official ideology. The transformation of the value system in official discourses aims at addressing the moral vacuum in contemporary Chinese society after the fall of Marxism ethics in face of the market economy (Bell, 2010). However, we can observe from the semantics of the guanxi tradition online

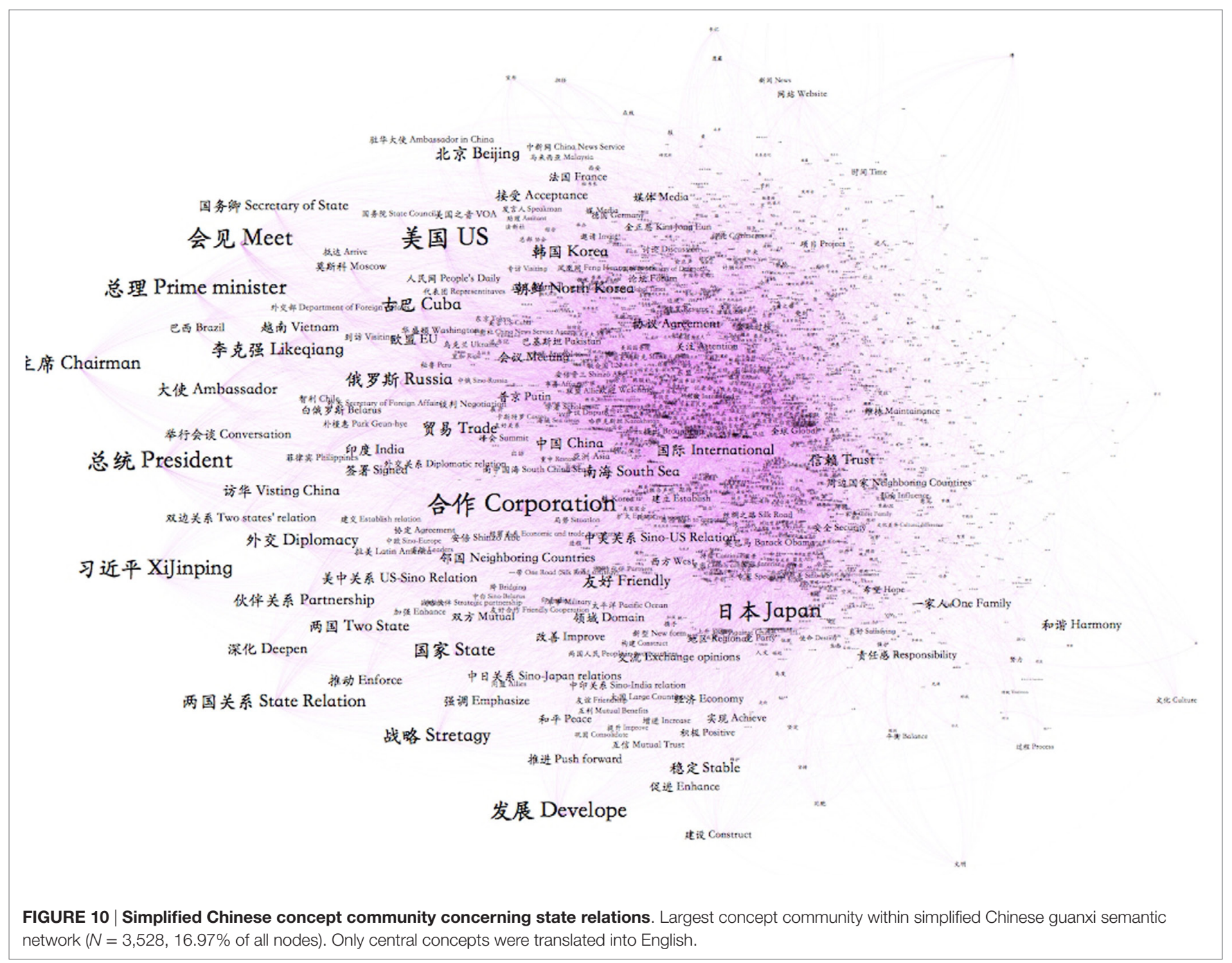




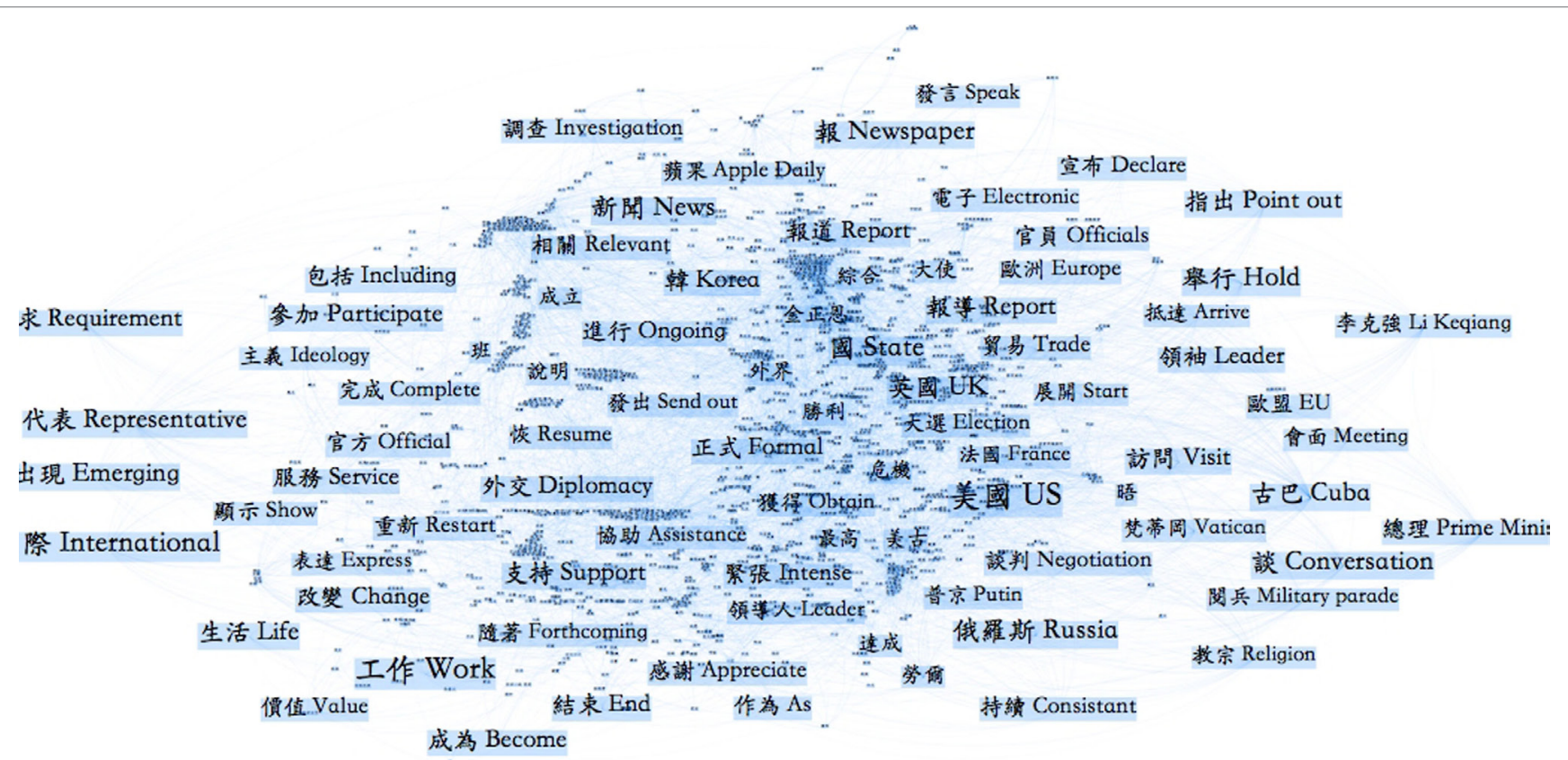

FIGURE 11 | Traditional Chinese concept community concerning state relations. Third largest concept community within the simplified Chinese guanxi semantic network ( $N=1,358,11.18 \%$ of all nodes). Only central concepts were translated into English.

TABLE 7 | Rank of node strength of central concepts in the largest subcommunity of simplified guanxi semantic network: states relations.

\begin{tabular}{lcc}
\hline Central concept & Node strength & $\begin{array}{c}\text { Rank of node strength } \\
\text { in the sub-community }\end{array}$ \\
\hline "Bilateral Relations" (“两国关系”) & 32.3743203 & 14 \\
"Diplomacy" (“外交”) & 29.6499375849962 & 17 \\
"Friendly" (“友好”) & 27.6214631944894 & 23 \\
"Family" (“家庭”) & 21.8933793753383 & 48 \\
"People's Daily" (“人民网”) & 17.59203054 & 69 \\
"VOA" (“美国之音”) & 16.4191469550132 & 80 \\
"Cuba" (“古巴") & 32.45306754 & 13 \\
"Russia” (“俄罗斯”) & 31.7798078805208 & 15 \\
\hline
\end{tabular}

The total number of central concepts in this sub-community is 176 .

TABLE 8 | Rank of node strength of central concepts in the third largest sub-community of traditional guanxi semantic network: states relations.

\begin{tabular}{lcc}
\hline Central concept & Node strength & $\begin{array}{c}\text { Rank of node strength in the } \\
\text { sub-community }\end{array}$ \\
\hline "Report” (“報道”) & 48.10576472 & 19 \\
"Diplomacy” (“外交”) & 46.22633854 & 21 \\
"Apple Daily" & 30.32274926 & 54 \\
(“蘋果日報”) & & 22 \\
"Visit” (“訪問”) & 45.87365648 & \\
\hline
\end{tabular}

The total number of central concepts in this sub-community is 68.

that there is a mismatch between the popular discourses and the official ideology. This might lead to a sense of uncertainty and confusion about the ongoing transformation of ideology or doctrines in the Mainland.

\section{Guanxi in Two Markets}

Our study also showed in the simplified Chinese guanxi semantic network, the concept guanxi bridges industries and the government, forming cliques in which members benefit each other through the exchange of political and economic resources. Such a phenomenon is also often the target of criticisms in the simplified Chinese discourses. Meanwhile, business guanxi in the traditional Chinese semantic network is separated from the political guanxi concept community. This clear division of politics and business ensures a fair environment for the market.

Whether or not political guanxi is intertwined with the business networks, and how political leverage is constrained to avoid corruption and rent-seeking behaviors mirror institutional differences in two Chinese societies.

The close-knit connection between political power and economic entities in the Mainland can be attributed to the lack of constraints over bureaucrats in Chinese state capitalism. Since in 1980s, the Chinese Communist Party has promoted a market economy featuring strong government control. With the market growth and capital accumulation, the lack of effective structural constraints on officials leads to rampant corruptions and rentseeking behaviors. The lack of efforts for political reform might lead to the continuing spread of corruption and rising dissatisfaction concerning the party's legitimacy. Eventually, this will result in criticism of and distrust in the government (Fukuyama, 2014). By contrast, in TW-HK-M, a globalized market and relatively effective constraints on bureaucratic power (Jones, 1994) help to prevent officials from using guanxi to obtain illegal profits. Guanxi connections in these market economies are more difficult to be manipulated by individuals. 


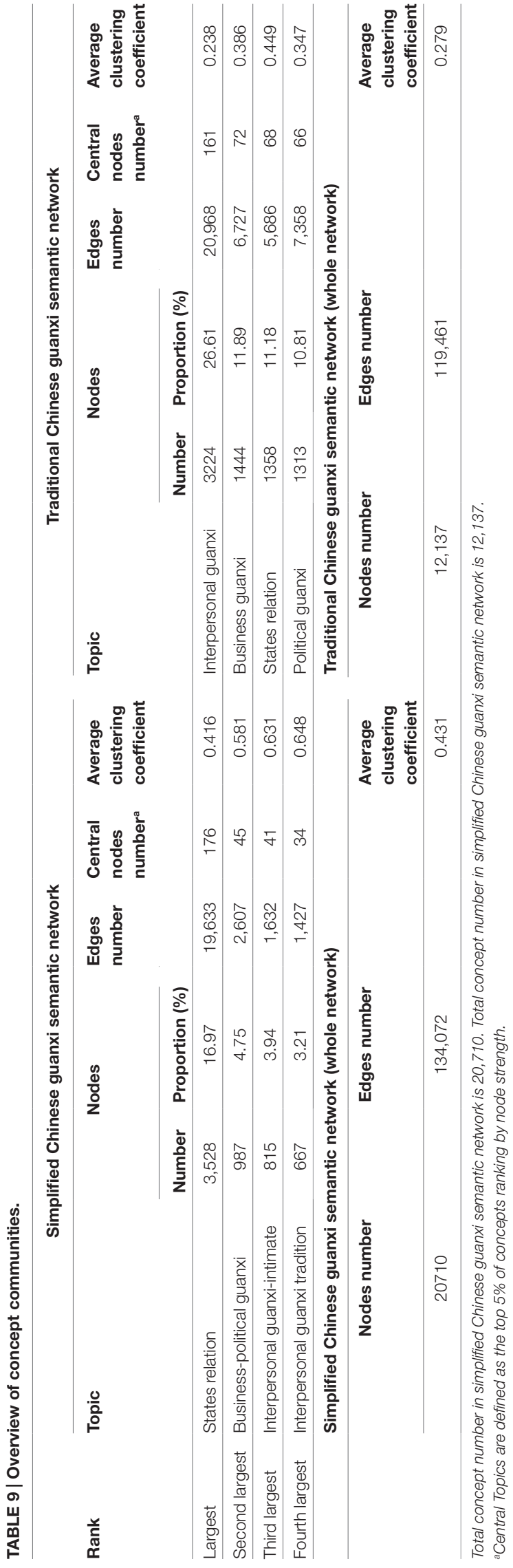

A regulated market economy requires clear laws formalizing the types of guanxi practices that are acceptable and those that are forbidden. This is not only important for the Chinese market economy but also significant for Chinese political legitimacy in the long run. Business guanxi in TW-HK-M demonstrates the possible variance of guanxi culture in a regulated market economy. For leaders in the Mainland, these economies might provide solutions for tackling rampant corruptions.

\section{Language and Culture: A Reflection}

While semantic networks generated from popular discourse could reflect the understanding of guanxi among Chinese Twitter users, there are still some limitations of the study.

First, Twitter is unfamiliar to most of Internet users in Mainland China due to the government block (the Great Firewall); in particular, it has not been used by people who live in rural China or who do not have sufficient technological skills to bypass the Internet block. This makes Mainland Twitter users a relatively special group of Chinese Internet users and also lacks representativeness of the general Chinese population. However, there is an advantage in using discourses of Mainland Twitter users to study guanxi. This group tends to be very sensitive to Chinese politics and is less constrained by government censorship, which allows for the observation of critical opinions concerning Chinese political guanxi. Second, as the relationship between language and mind is complex, popular discourses on guanxi could not contribute more details regarding the dynamic process of practicing guanxi in offline settings. Third, concepts represented by segmented words, only provide a limited window into understanding what people think about or believe in, and thus certain context of the concepts is lost when processing language.

To conclude, this study revisited guanxi culture in different Chinese societies by analyzing its linguistic representations in popular discourses. The concept guanxi bridges individuals and societies in the Chinese context. Reifications of the concept guanxi had not only provided understanding of guanxi in contemporary Chinese societies but had also served as an interpretive device for studying the political and economic systems in which guanxi cultures are embedded.

\section{ETHICS STATEMENT}

The University of Oxford Central University Research Ethics Committee has reviewed and granted ethical clearance to this study.

\section{AUTHOR CONTRIBUTIONS}

$\mathrm{Pu}$ Yan and Taha Yasseri designed the research. Pu Yan collected and analyzed the data; wrote the article. Both authors have edited and approved the article.

\section{ACKNOWLEDGMENTS}

The authors are grateful to Ralph Schroeder for his insights and feedbacks on the theoretical discussion of guanxi culture. We also appreciate valuable feedbacks from the two anonymous reviewers. 


\section{FUNDING}

The author declares that the research was conducted in the absence of any commercial or financial relationships that could be construed as a potential conflict of interest.

\section{REFERENCES}

Baker, H.D.R. (1979). Chinese Family and Kinship. New York, NY: Columbia University Press.

Barmé, G.R. (2000). In the Red: On Contemporary Chinese Culture. New York, NY: Columbia University Press.

Barrat, A., Barthelemy, M., Pastor-Satorras, R., and Vespignani, A. (2004). The architecture of complex weighted networks. Proceedings of the National Academy of Sciences of the United States of America 101: 3747-52. doi:10.1073/ pnas.0400087101

Bastian, M., Heymann, S., and Jacomy, M. (2009). Gephi: An Open Source Software for Exploring and Manipulating Networks. Available at: https://gephi.org/ publications/gephi-bastian-feb09.pdf

Bell, D.A. (2010). China's New Confucianism: Politics and Everyday Life in a Changing Society. Princeton, NJ: Princeton University Press.

Bian, Y. (1994). Guanxi and the allocation of urban jobs in China. The China Quarterly 140: 971-99. doi:10.1017/S0305741000052863

Bian, Y. (2002). Institutional holes and job mobility processes: guanxi mechanisms in China's emergent labour markets. In Social Connections in China: Institutions, Culture, and the Changing Nature of Guanxi, Edited by T. Thomas, G. Doug, and D. Wank, 117-136. Cambridge, England: Cambridge University Press.

Bian, Y., and Ang, S. (1997). Guanxi networks and job mobility in China and Singapore. Social Forces 75: 981-1005. doi:10.2307/2580527

Bouma, G. (2009). Normalized (pointwise) mutual information in collocation extraction. In Proceedings of GSCL, 31-40. Potsdam: German Society for Computational Linguistics and Language Technology.

Burt, R.S. (1992). Structural Holes. Cambridge, MA: Harvard University Press.

Burt, R.S. (2002). Bridge decay. Social Networks 24: 333-63. doi:10.1016/ S0378-8733(02)00017-5

Church, K.W., and Hanks, P. (1990). Word association norms, mutual information, and lexicography. Computational Linguistics 16: 22-9.

Cohen, M.L. (1970). Developmental process in the Chinese domestic group. In Family and Kinship in Chinese Society, Edited by M. Freedman, 21-36. Stanford, CA: Stanford University Press.

Collins, A., and Quillian, R. (1969). Retrieval time from semantic memory. Journal of Verbal Learning and Verbal Behaviour 8: 240-7. doi:10.1016/ S0022-5371(69)80069-1

Danowski, J.A. (1993). Network analysis of message content. In Progress in Communication Sciences XII, Edited by G. Barnett and W. Richards, 197-222. Norwood, NJ: Ablex.

Danowski, J.A. (2013). WORDij Version 3.0: Semantic Network Analysis Software. Chicago: University of Illinois at Chicago.

Doerfel, M.L. (1998). What constitutes semantic network analysis? A comparison of research and methodologies. Connections 21: 16-26.

Evans, V. (2005). Evolution of semantics. In Elsevier Encyclopaedia of Language and Linguistics, Edited by K. Brown, 345-352. Burlington, MA: Elsevier.

Fei, X.T. (1992). From the Soil: The Foundations of Chinese Society. Berkeley, CA: University of California Press.

Fellbaum, C. (1998). WordNet. Oxford, England: Blackwell Publishing Ltd.

Firth, J.R. (1957). Papers in Linguistics (1934-1951). London, England: Oxford University Press.

Freeman, C.A., and Barnett, G.A. (1994). An alternative approach to using interpretative theory to examine corporate messages and organizational culture. In Organizational Communication Emerging Perspective IV, Edited by L. Thayer and G.A. Barnett, 60-73. Norwood, NJ: Ablex.

Fukuyama, F. (2014). Political Order and Political Decay: From the Industrial Revolution to the Globalization of Democracy. London, England: Profile Books Ltd.

\section{SUPPLEMENTARY MATERIAL}

The Supplementary Material for this article can be found online at http://journal.frontiersin.org/article/10.3389/fdigh.2017.00011/ full\#supplementary-material.

Gold, T. (1986). State and Society in the Taiwan Miracle. New York, NY: M. E. Sharpe, Inc.

Guthrie, D. (1998). The declining significance of guanxi in China's economic transition. The China Quarterly 154: 254-82. doi:10.1017/ S0305741000002034

Hamilton, G. (1998). Patterns of Asian network capitalism. In Networks, Markets, and the Pacific Rim: Studies in Strategy, Edited by W.M. Fruin, 181-199. New York, NY: Oxford University Press.

Hsing, Y.T. (1998). Making Capitalism in China: The Taiwan Connection. New York, NY: Oxford University Press.

Hwang, K.K. (1987). Face and favour: the Chinese power game. American Journal of Sociology 92: 944-74. doi:10.1086/228588

Jacobs, J.B. (1979). A preliminary model of particularistic ties in Chinese political alliances: Kan-ching and Kuan-his in a rural Taiwanese township. The China Quarterly 78: 237-73. doi:10.1017/S0305741000040467

Jacomy, M., Venturini, T., Heymann, S., and Bastian, M. (2014). ForceAtlas2, a continuous graph layout algorithm for handy network visualization designed for the Gephi software. PLOS ONE 9:e98679. doi:10.1371/journal.pone. 0098679

Jankowiak, W. (2008). Practicing connectiveness as kinship in urban China. In Chinese Kinship: Contemporary Anthropological Perspectives, Edited by S. Brandtstädter and G.D. Santos. London, England: Routledge, 67-91.

Jensen, L.M. (1997). Manufacturi Eighbourhooism: Chinese Traditions \& Universal Civilization. Durham, NC: Duke University Press.

Jones, C.A. (1994). Capitalism, globalization and rule of law: an alternative trajectory of legal change in China. Social \& Legal Studies 3: 195-221. doi:10.1177/096466399400300201

Jurafsky, D., and Martin, J.H. (2014). Speech and Language Processing. 2nd ed. Harlow, England: Pearson.

King, A.Y. (1985). The individual and group in confucianism: a relational perspective. In Individualism and Holism: Studies in Confucian and Taoist Values, Edited by D.J. Munro, 57-67. Michigan: Centre for Chinese Studies, University of Michigan.

King, A.Y. (1991). Kuhishsi and network building: a sociological interpretation. Daedalus 120: 63-84.

Kipnis, A.B. (1996). The language of gifts: managing guanxi in a North China village. Modern China 22: 285-314. doi:10.1177/009770049602200302

Kipnis, A.B. (1997). Producing Guanxi: Sentiment, Self, and Subculture in a North China Village. London, England: Duke University Press.

Kozima, H., and Furugori, T. (1993). Similarity between words computed by spreading activation on an English dictionary. In Proceedings of the Sixth Conference on European Chapter of the Association for Computational Linguistics (Utrecht: Association for Computational Linguistics), 232-239.

Liang, S. (1987). Outline of Chinese Culture. Hong Kong: Joint Publishing.

Lin, L.H., and Ho, Y.L. (2009). Confucian dynamism, culture and ethical changes in Chinese societies: a comparative study of China, Taiwan, and Hong Kong. The International Journal of Human Resource Management 20: 2402-17. doi:10.1080/09585190903239757

Lin, N. (2001). Guanxi: a conceptual analysis. In The Chinese Triangle of Mainland China, Taiwan, and Hong Kong: Comparative Institutional Analyses, Edited by A.Y. So. London, England: Greenwood Press, 153-166.

Luo, J.D. (1997). The significance of networks in the initiation of small businesses in Taiwan. Sociological Forum 12: 297-317. doi:10.1023/A:1024654017270

Ma, W., and Cheng, J.Y. (2010). The evolution of entrepreneurs' social networks in China: patterns and significance. Journal of Contemporary China 19: 891-911. doi:10.1080/10670564.2010.508590

Newman, M.E. (2006). Modularity and community structure in networks. Proceedings of the National Academy of Sciences of the United States of America 103: 8577-82. doi:10.1073/pnas.0601602103 
Newman, M.E., Watts, D.J., and Strogatz, S.H. (2002). Random graph models of social networks. Proceedings of the National Academy of Sciences of the United States of America 99: 2566-72. doi:10.1073/pnas.012582999

Oxford Dictionary of English. (2010). Oxford Dictionary of English. 3rd ed. Oxford, England: Oxford University Press.

Potter, P.B. (2002). Guanxi and the PRC legal system: from contradiction to complementarity. In Social Connections in China: Institutions, Culture, and the Changing Nature of Guanxi, Edited by T. Thomas, G. Doug, and D. Wank, 179-196. Cambridge, England: Cambridge University Press.

Pye, L.W. (1992). The Spirit of Chinese Politics. London, England: Harvard University Press.

Quillian, R. (1963). A Notation for Representing Conceptual Information: An Application to Semantics and Mechanical English Paraphrasing. Santa Monica, CA: System Development Corporation.

Saussure, F. (2011). Course in General Linguistics. New York, NY: Columbia University Press.

Smart, A. (1999). Expressions of interest: friendship and guanxi in Chinese societies. In The Anthropology of Friendship, Edited by S. Bell and S. Coleman, 119-136. New York, NY: Berg.

Tsai, L.L. (2007). Solidary groups, informal accountability, and local public goods provision in rural China. American Political Science Review 101: 355-72. doi:10.1017/S0003055407070153

Walder, A.G. (1995). Career mobility and the communist political order. American Sociological Review 60: 309-28. doi:10.2307/2096416

Wank, D.L. (1999). Commodifying Communism: Business, Trust, and Politics in a Chinese City. New York, NY: Cambridge University Press.

Weber, M. (1964). The Religion of China: Confucianism and Taoism. London, England: Collier MacMillan.

Wellman, B. (2001). The persistence and transformation of community: From neighbourhood groups to social networks. Report to the Law Commission of Canada. Ottawa, Ontario: Law Commission of Canada.

Wellman, B., Chen, W., and Dong, W. (2002). Networking guanxi. In Social Connections in China: Institutions, Culture, and the Changing Nature of Guanxi,
Edited by T. Thomas, G. Doug, and D. Wank, 221-242. Cambridge, England: Cambridge University Press.

Wong, S. (1986). Modernization and Chinese culture in Hong Kong. The China Quarterly 106: 306-25. doi:10.1017/S0305741000038595

Wong, S.L. (1985). The Chinese family firm: a model. British Journal of Sociology 36: 58-72. doi: 10.2307/590402

Xiao, Z., and Tsui, A.S. (2007). When brokers may not work: the cultural contingency of social capital in Chinese high-tech firms. Administrative Science Quarterly 52: 1-31. doi:10.2189/asqu.52.1.1

Xin, K.K., and Pearce, J.L. (1996). Guanxi: connections as substitutes for formal institutional support. Academy of Management Journal 39: 1641-58. doi: $10.2307 / 257072$

Yan, Y. (1996). The culture of guanxi in a North China village. The China Journal 35: 1-25. doi:10.2307/2950274

Yang, M.M.H. (1994). Gifts, Favors, and Banquets: The Art of Social Relationships in China. London, England: Cornell University Press.

Yi, Y.G. (2014). Fighting Systematic Corruption: Regulating "Guanxi Circles in Officialdom”. Xinhua Daily Telegraph. Available at: http://news.xinhuanet.com/ $\operatorname{mrdx} / 2014-06 / 27 / \mathrm{c} \_133441215 . h t m$

Yuan, E.J., Feng, M., and Danowski, J.A. (2013). "Privacy" in semantic networks on Chinese social media: the case of Sina Weibo. Journal of Communication 63: 1011-31. doi:10.1111/jcom. 12058

Conflict of Interest Statement: The authors declare that the research was conducted in the absence of any commercial or financial relationships that could be construed as a potential conflict of interest.

Copyright ( $(2) 17$ Yan and Yasseri. This is an open-access article distributed under the terms of the Creative Commons Attribution License (CC BY). The use, distribution or reproduction in other forums is permitted, provided the original author(s) or licensor are credited and that the original publication in this journal is cited, in accordance with accepted academic practice. No use, distribution or reproduction is permitted which does not comply with these terms. 